\title{
ISSUES ON BUILDING KAZAKHSTAN GEOSPATIAL PORTAL TO IMPLEMENT E- GOVERNMENT
}

\author{
K. Sagadiyev ${ }^{\text {a }}$, H. K. Kang ${ }^{b}$, K. J. Li ${ }^{\mathrm{c}}$ \\ a National Information Technologies, Astana, Kazakhstan, kuat.Sagadiyev@nitec.kz \\ ${ }^{\text {b }}$ GIS Research Division, Korea Research Institute for Human Settlements, Anyang, South Korea, , kang.krihs@gmail.com \\ ${ }^{\mathrm{c}}$ Department of Computer Science and Engineering, Pusan National University, Pusan, South Korea, lik@pnu.edu
}

\section{Commission II, ThS14 - Recent Developments in Open Data}

KEY WORDS: e-Government, Geospatial Open Data, Web portal, Open Source

\begin{abstract}
:
A main issue in developing e-government is about how to integrate and organize many complicated processes and different stakeholders. Interestingly geospatial information provides an efficient framework to integrate and organized them. In particular, it is very useful to integrate the process of land management in e-government with geospatial information framework, since most of land management tasks are related with geospatial properties. In this paper, we present a use-case on the e-government project in Kazakhstan for land management. We develop a geoportal to connect many tasks and different users via geospatial information framework. This geoportal is based on open source geospatial software including GeoServer, PostGIS, and OpenLayers. With this geoportal, we expect three achievements as follows. First we establish a transparent governmental process, which is one of main goal of e-government. Every stakeholder monitors what is happening in land management process. Second, we can significantly reduce the time and efforts in the government process. For example, a grant procedure for a building construction has taken more than one year with more than 50 steps. It is expected that this procedure would be reduced to 2 weeks by the geoportal framework. Third we provide a collaborative environment between different governmental structures via the geoportal, while many conflicts and mismatches have been a critical issue of governmental administration processes.
\end{abstract}

\section{INTRODUCTION}

Tasks in a government are very often composed of complicated processes and many different stakeholders are involved. A main issue in developing e-government (Siau et al., 2005) is about how to integrate and organize many complicated processes and different stakeholders. Interestingly geospatial information (Peter F., 2011) provides an efficient framework to integrate and organized them. In particular, it is very useful to integrate the process of land management in e-government with geospatial information framework, since most of land management tasks are related with geospatial properties. In this paper, we present a use-case on the e-government project in Kazakhstan for land management.

The main goal of this project is to integrate the land management process in the Kazakhstan government including many stakeholders of the process. We develop a geoportal (Xin H., et al., 2012) to connect many tasks and different users via geospatial information framework. This geoportal is based on open source geospatial software including GeoServer, PostGIS, and OpenLayers. The users of this geoportal are divided into geospatial data producers/managers and geospatial data consumers and accordingly the geoportal provides two types of functions, one for G2G (Government to Government) and the other for G2C (Government to Citizens). The first type is to support the tasks within the government such as the collection, production, and authorization of land information including geospatial information. And the second type is to provide a more open and easy access of land information to public.
With this geoportal, we expect three achievements as follows. First we establish a transparent governmental process, which is one of main goal of e-government. Every stakeholder monitors what is happening in land management process. Second, we can significantly reduce the time and efforts in the government process. For example, a grant procedure for a building construction has taken more than one year with more than 50 steps. It is expected that this procedure would be reduced to 2 weeks by the geoportal framework. Third we provide a collaborative environment between different governmental structures via the geoportal, while many conflicts and mismatches have been a critical issue of governmental administration processes.

This paper is organized into four main sections. The second section of this paper introduces the current GIS status of republic of Kazakhstan with GIS practices of local governments. The third section describes the concept of Kazakhstan NGIS portal, its architecture and implementation results. It will present issues on implement Kazakhstan NGIS portal. Finally, the last section concludes pointing to future work.

\section{CURRENT STATUS OF KAZAKHSTAN GIS}

\subsection{Geographic/Cartographic Data}

There are very limited geographic/cartographic materials in the Republic of Kazakhstan. $80 \%$ of map including topographic maps does not correspond to the state toponymy or information

\footnotetext{
* Corresponding author
} 
in the real the according to the Ministry of Regional Development of the Republic of Kazakhstan (RKMRD). The discordance can lead to significant economic losses on an emergency situation.

Land Management Committee under the RKMRD pointed out six main issues to be overcome in the field of geodesy and cartography, for instance, loss of state geodetic network, longterm update frequency (around 20 years), not full coverage across even a seismically active area and the Caspian region of Kazakhstan. In addition, general technological backwardness of geodetic enterprises and lack of human resources were mentioned as well. Incorrect products due to multiple coordinate reference systems with the ellipsoid Krasovsky in 1942, the ellipsoid Krasovsky in 1963 and local coordinate systems based on the cross-cylindrical projection Gauss-Kruger was also pointed out.

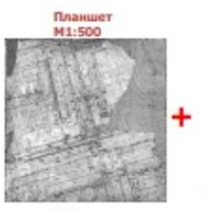

$+$

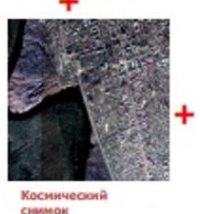

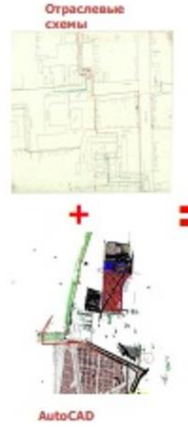

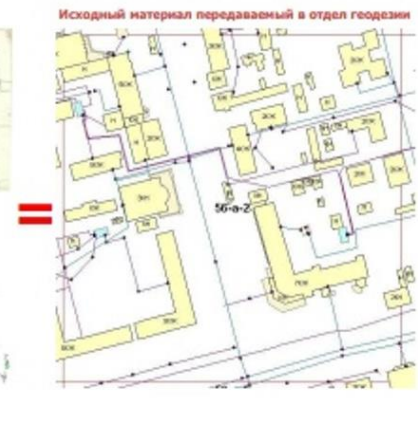

Figure 1. Uralsk Cadastral + Facility Digital Map

\subsection{Geographic Information Systems}

Most ministries in the republic of Kazakhstan provide their public business in an automated way. For this, 290 information systems are running as a part of e-Government such as Address Register national database, Real Estate Register state database, State Land Cadastre information system of the Republic of Kazakhstan", and so on. In case of Ministry of Emergency (MOE), 60\% of their businesses (46 kinds) is automated according to the automation assessment of government business in 2012. Geo-monitoring information management system for emergency situation to protect human settlements and facilities and to manage floods or landslides is an instance of the automated businesses of the MOE. Local governments such as Uralsk, Almaty, Kyzylorda and Mangistau also automated their business by using GIS technologies as shown in figure 2 .

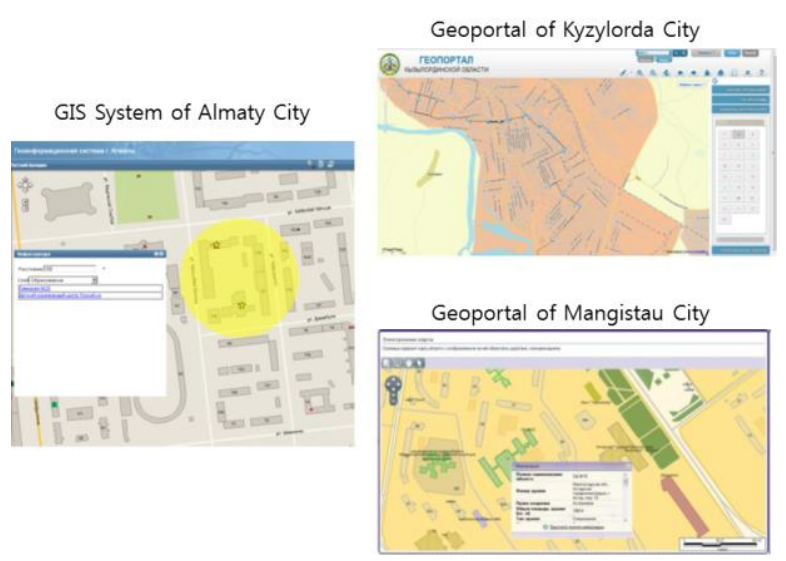

Figure 2. GIS systems of local governments in Kazakhstan
Since many public agencies have developed GIS system separately, the issue of interoperability and sharing is getting apparent.

\subsection{The necessity of NGIS in Kazakhstan}

When map-related functions in e-government of Kazakhstan are provided by an integrated service called national geographic information system (NGIS), many positive effects can be resulted. First of all, as the result of an analysis of public services registry conducted by JSC National Information Technologies of the republic of Kazakhstan (JSC NITEC), 71 services among 647 public services were related to the use of map information. It can be possible to save budget if the 71 services were integrated instead of operating them separately. JSC NITEC said that 944433774 tenge (Kazak money) per year can be saved when the 71 services will be provided through NGIS which provides map-related services.

Second, it will be possible for national mapping authority or land committee to save the cost of collection/update of spatial data by sharing it among government agencies without additional cost. It will be easier to provide up-to-date spatial data to consumers through NGIS which is a channel sharing spatial data among agencies.

Third, business process using spatial information (digital map) can be integrated into NGIS, so it will be effective to make business process shorter. Consequently, citizen will get better public services.

The NGIS will a part of Kazakhstan open government (Stefan K., et al., 2012) that was established to screen and to promote human resources where all citizens have equal rights and opportunities that ensure a high professional level and transparency of government activities. It is called $\mathrm{KZOpenGov}$ (e-Government) and it consists of 5 components; open data portal, open budget portal, open dialogue portal, open law and regulations portal and agencies' performance assessment portal. Open data portal was launched in 2013 and provides 325 datasets, 10 applications and APIs to access the system. NGIS is developing as a part of Open data portal.

\section{KAZAKHSTAN NGIS PORTAL}

\subsection{Concept of Kazakhstan NGIS}

National "Information Kazakhstan- 2020" Program was approved with Decree by President of the Republic of Kazakhstan No. 464 of 8 January 2013 as a part of eGovernment development. One of the goal is to integrate national geo-informational environment that would provide government agencies with access to the up-to-date high-quality complete geo-informational content with national databases recording items (Line H., et el., 2014).

The figure 3 shows the concept of Kazakhstan NGIS Portal. Its operational mechanism is as follows. First an engineer surveys new building when a citizen requests it. Then, the engineer sends a file with geospatial information to a citizen as a result of the survey. The citizen registers the file via NGIS portal to get a permission/approval from land resource committee of Kazakhstan. When a new file is registered on NGIS portal, it delivers the new data to a proper agency in charge of the data. After an official reviews correctness of the data, the official decide approval/reject of the request through NGIS. If the 
submitted geospatial data is approved, then the geospatial data will be inserted into a national database and publish it to share with people.

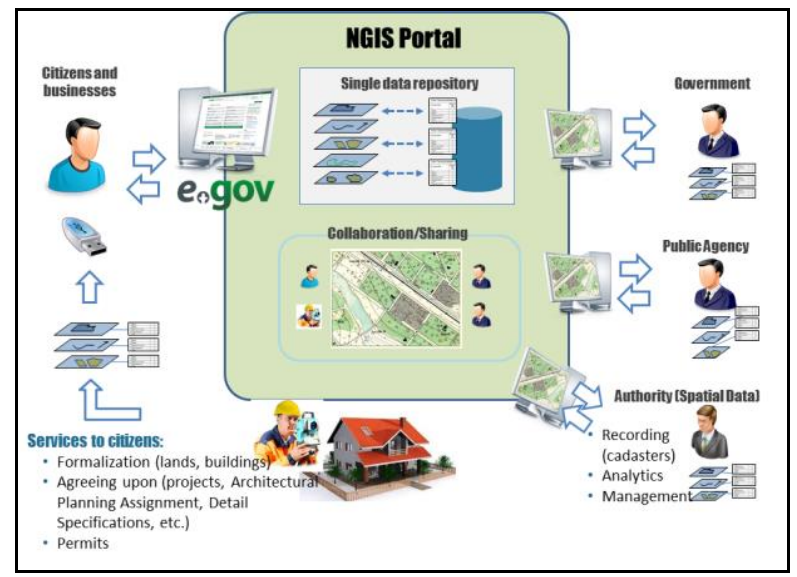

Figure 3. Concept of Kazakhstan NGIS Portal

\subsection{Kazakhstan NGIS Architecture and Implementation}

The architecture of Kazakhstan NGIS Portal is shown in figure 4. On the client side, the application is built on OpenLayers which is an open source JavaScript library for displaying map data in web browsers. Citizens need to register to use services of the NGIS portal. It will be managed by User authorization module.

Users registered can submit their geospatial data with a file type, or can create manually on the NGIS portal. When geospatial data is submitted, NGIS portal validate the quality of the submitted data such as undershoot, overshoot, topological inconsistency, and so on. When the submitted data is evaluated as a completed one, the data is transferred to an authorized organization to get an approval. Users can check on where their request is going via Process Monitoring module.

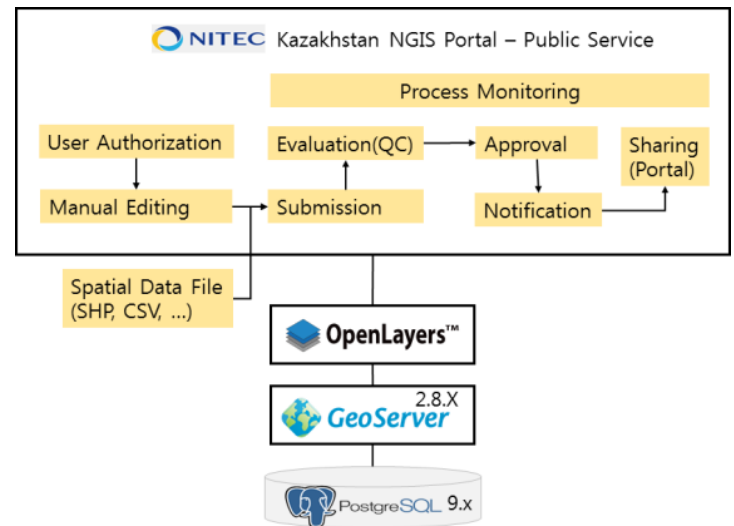

Figure 4. Kazakhstan NGIS Portal Architecture

Three kinds of DBs are in PostgreSQL database to manage submitted data, evaluated data and approved data separately, When the submitted data is approved, the NGIS portal notifies the acceptance to user by using Notification module and publish it on NGIS portal to share with people.
The Kazakhstan NGIS Portal is developing with PostgreSQL 9.x, Oracle JRD7, Tomcat7, OpenLayers 3.0 and GeoServer 2.8.x.

The figure 5 and the figure 6 shows screen shots of a client side. OpenStreetMap was used as a base data for Kazakhstan NGIS portal since there is not nationwide and seamless datasets in Kazakhstan. When a user registers NGIS portal, their identity is guaranteed by e-certification system of Kazakhstan government. A user can draw a geospatial object by using a manual editing button and insert attribute information of the geospatial object in the figure 6.

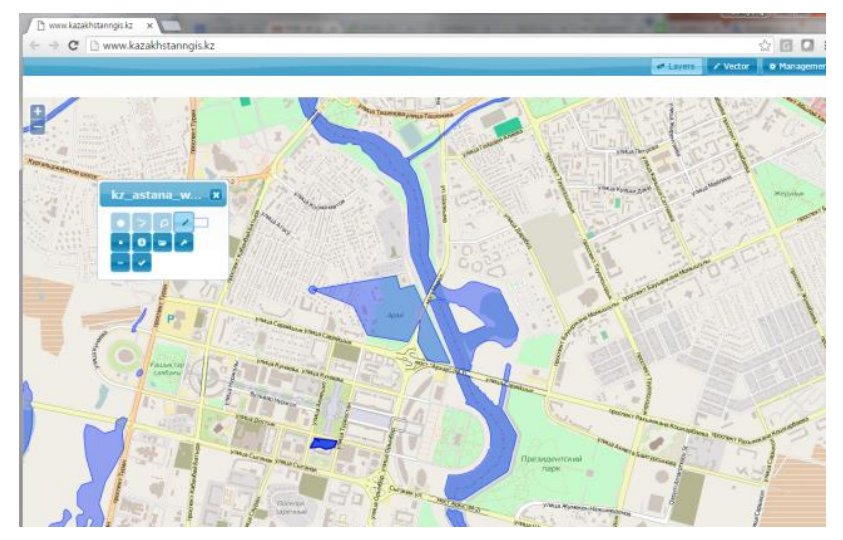

Figure 5. Kazakhstan NGIS Portal

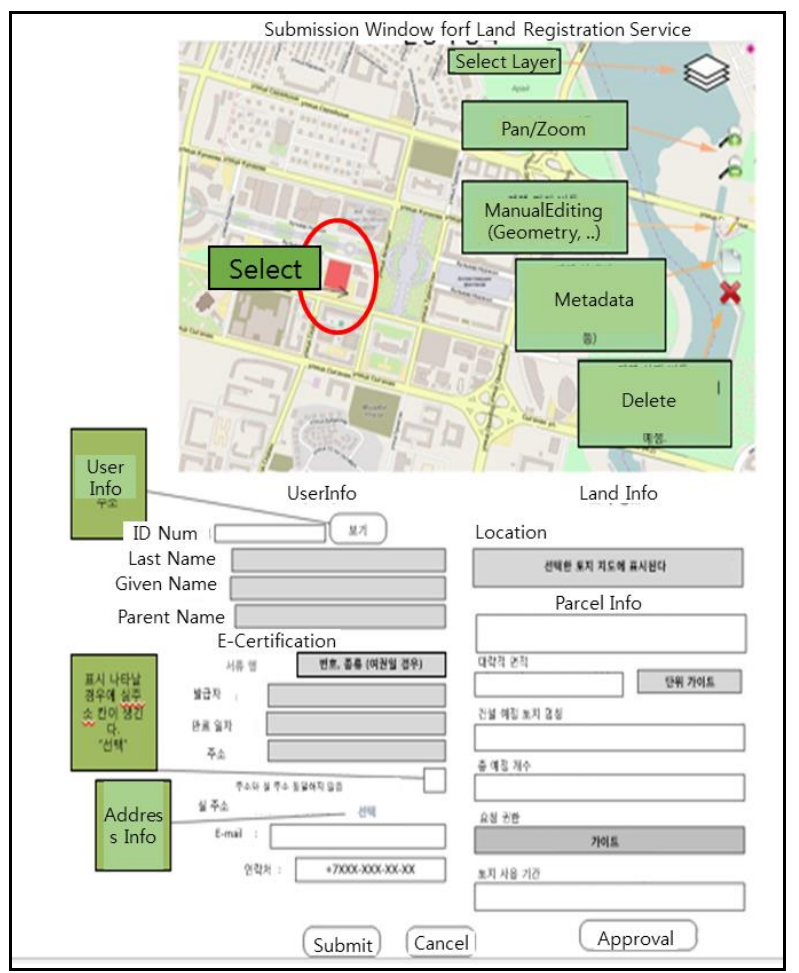

Figure 6. Kazakhstan NGIS Portal - Land Submission

\subsection{Issues on building Kazakhstan NGIS}

Kazakhstan NGIS portal aims to enhance the efficiency of government business by integrating the business process 
divided in different government agencies. That is, the NGIS portal is a collaborative system based on geospatial information. For sharing of geospatial data among different agencies, geospatial standards are necessary. However, there are no geospatial standards such as data specification, service interfaces, data format and coordination systems in Kazakhstan. Thus developing geospatial standards is definitely an important issue on building Kazakhstan NGIS.

Regulation describing standardized business process and its form should be published to service Kazakhstan NGIS portal. Building national common dataset covering whole country is needed. Prior to the building national dataset, data specification which describes standardized criteria for data completeness should be published. Capacity building of human resources in terms of data, technologies, policy and theory will be an important issue because all of the works on building Kazakhstan NGIS are conducted by people, for instance implementing, operating, building the Kazakhstan NGIS. Establishing a master-plan and legislation/regulation should be pointed out to proceed sustainable development of Kazakhstan NGIS.

\section{CONCLUSION}

Many countries are developing government-driven geospatial information system to improve transparency and efficiency of a government. Kazakhstan is one of the countries. Government agencies and local governments in Kazakhstan have been developing its own GIS system without considering interoperability and sharing.

This paper presented Kazakhstan NGIS Portal as a collaborative e-government platform based on geospatial information. This contribution also presented the practice of implementing the NGIS portal by using open source software. The open source approach can reduce costs of building and maintenance of Kazakhstan NGIS. Sharing geospatial information via one portal can reduce the process of complicated business among different agencies as well. It will be much easier for users to get a public service. In addition, the open source approach will contribute on building capacity of GIS human resource because of source codes opened. Geospatial standards, data specification, policy and plan should be developed in the future for sustainable development of Kazakhstan NGIS.

\section{ACKNOWLEDGEMENTS (OPTIONAL)}

This research was supported by a grant (14NSIP-B080144-01) from National Land Space Information Research Program funded by Ministry of Land, Infrastructure and Transport of Korean government.

\section{REFERENCES}

Stefan K., Bastiaan L, 2012. Brave New Open Data World? International Journal of Spatial Data Infrastructures Research, Vol.7, pp.196-206.

Xin H., Hans P., Anders Ö., 2012. Geoportal Usability Evaluation. International Journal of Spatial Data Infrastructures Research, Vol.7, pp. 88-106.

Peter F., 2011. Geospatial Information and Geographic Information Systems (GIS): An Overview for Congress., Congressional Research Service, 7-5700 R41825, pp. 1-19.
OECD, 2015. OECD Digital Government Studies: Open Government Data Review of Poland. OECD, pp. 35-53.

Siau, K. and Long Y., 2005. Synthesizing e-government stage models - a meta-synthesis based on meta-ethnography approach. Industrial Management \& Data Systems, Vol.105(4). pp. 443458 .

Line H., Lasse B., and Lise S., 2014. Mature e-Government based on spatial data -legal implications, International Journal of Spatial Data Infrastructures Research, Vol.9, pp. 131-149. 